\title{
O livro didático de língua inglesa como espaço para promoção do letramento informacional
}

\author{
Luciana do Amaral Teixeira \\ (Universidade Estácio de Sá/SME-RJ/FAETEC)
}

\begin{abstract}
Resumo
Este artigo objetiva incentivar a promoção do letramento informacional demonstrando como o mesmo pode ser praticado em um exercício complementar a uma atividade extraída de um livro didático de língua inglesa. A intenção é contribuir para a formação de indivíduos capazes de aprender a aprender que sejam críticos e autônomos.
\end{abstract}

Palavras-chave: ensino de inglês, letramento informacional, livro didático.

\begin{abstract}
The objective of this article is to encourage the promotion of information literacy through the demonstration of an exercise that complements an activity extracted from an English textbook. The intention is to contribute to the formation of individuals who are able to learn how to learn and who are critical and autonomous.
\end{abstract}

Keywords: English teaching, information literacy, textbooks

\section{INTRODUÇÃO}

Durante muito tempo, o termo letramento esteve associado às capacidades de leitura e escrita. Entretanto, em função da percepção de novas formas de lidar com o mundo e da necessidade de novas habilidades para tal, esse conceito foi reformulado e passou a contemplar novos letramentos, como o informacional. De modo geral, o letramento informacional se concentra na forma como os indivíduos lidam com as informações que o rodeiam em sua vida cotidiana. Nesse sentido, trata-se de uma habilidade essencial, pois ajuda as pessoas a tirarem proveito do novo ambiente informacional - aberto e colaborativo - tanto na vida pessoal quanto na acadêmica e na profissional.

Reconhecendo que o letramento informacional deve ser formalmente ensinado e praticado no ambiente escolar, este artigo discute uma proposta de complementação a uma atividade presente na coleção WAY TO GO!, voltada ao ensino de inglês para o ensino médio. A intenção é propor aos alunos um exercício complementar que lhes dê a oportunidade 
de perpassar pelos pilares que sustentam o letramento informacional e, assim, ampliar sua percepção a respeito da importância da localização e do uso da informação.

A motivação para este trabalho vem da recorrente insatisfação dos professores com relação ao produto final produzido pelos alunos quando uma pesquisa lhes é solicitada. O que se quer com o exemplo de atividade aqui demonstrado é chamar atenção para o fato de que, ao contrário do que se pode crer, o ensino sobre como proceder nas atividades que demandam recuperação e uso da informação não cabe somente ao bibliotecário. Cada vez mais, os alunos estão buscando informações fora da biblioteca, no ambiente virtual acessível a partir de qualquer lugar, e, portanto, precisam ser orientados sobre como fazê-lo de maneira a não incorrer em problemas comuns, como o plágio. Assim, cabe aos professores de todas as disciplinas orientar seus estudantes sobre o caminho adequado a trilhar na realização de pesquisas.

\section{FUNDAMENTAÇÃO TEÓRICA}

Há mais de três décadas, diversos estudos acerca do tema "letramento" vêm sendo desenvolvidos. Durante grande parte desse tempo, o termo foi utilizado estritamente para fazer referência à capacidade de ler e escrever; entretanto, em função da percepção das múltiplas formas de letramento praticadas no novo milênio, o conceito foi reformulado e passou a contemplar novas práticas sociais. Conforme comenta Soares (1998, p.49), "há diferentes tipos e níveis de letramento, dependendo das necessidades, das demandas do indivíduo e de seu meio, do contexto social e cultural".

\section{Letramento informacional}

O letramento informacional, do inglês information literacy, faz referência ao conjunto de habilidades que permite que se localize, selecione, acesse, organize e use informações para gerar conhecimento. Embora não seja um tema recente, visto que pesquisas acerca desse tipo de letramento surgiram nos Estados Unidos na década de 1970, o mesmo começa a ser alvo de estudos brasileiros somente a partir do ano 2000. Nessa época, utilizava-se o termo “alfabetização informacional" para descrever o processo que "inclui a habilidade de localizar, processar e usar informação eficazmente, independentemente do mecanismo de obtenção e do tipo de formato no qual aquela informação aparece" (CAREGNATO, 2000, p.50). Para Gasque (2012, p.38), 
o letramento informacional é um processo de aprendizagem, compreendido como ação contínua e prolongada, que ocorre ao longo da vida. O sentido da aprendizagem relaciona-se à construção do conhecimento, inerente ao ser humano, que perpassa as várias atividades do comportamento informacional, considerando as experiências e informações, que abrange as atitudes, as disposições morais e o cultivo das apreciações estéticas. Assim, entende-se tal processo como o conjunto das mudanças relativamente permanentes resultantes das inter-relações entre a nova informação, a reflexão e a experiência prévia, sem desconsiderar as interações do indivíduo com o meio social.

Comumente associado aos estudos das áreas de Ciências da Informação e Biblioteconomia, o letramento informacional é uma demanda social de diferentes segmentos; visto que

todos usam a informação; seja enquanto cidadãos, trabalhadores, solucionadores de problemas ou aprendizes no longo prazo. Tradicionalmente, as escolas oferecem um ambiente no qual "se aprende a aprender". As principais competências de aprendizado incluem a formulação de questões, o acesso a fontes potenciais de informação, a avaliação da informação conforme sua pertinência e exatidão, a organização da informação e, por fim, a aplicação da informação para responder as questões originais - a última e mais valiosa etapa do processo. $O$ que motiva o aprendiz não é somente encontrar a informação, mas utilizá-la. (DOYLE, 1994, p.1)

Assim sendo, promover sua prática é responsabilidade de todos aqueles envolvidos no processo formal de educação, em qualquer que seja a disciplina ou área de conhecimento. Conforme ratifica The New London Group (in COPE\&KALANTZIS, 2000, p.20),

se fosse possível definir, de maneira geral, a missão da educação, poder-se-ia dizer que seu propósito fundamental é garantir que todos os estudantes se beneficiem do aprendizado de modo que consigam participar integralmente na vida pública, na comunidade e na vida econômica. A pedagogia é uma relação de ensino e aprendizagem que viabiliza o potencial para construção das condições de aprendizado que levarão à participação completa e igualitária. Espera-se que a pedagogia de letramentos, mais especificamente, desempenhe um papel crucial no cumprimento desta missão.

A UNESCO - Organização das Nações Unidas para Educação, Ciência e Cultura acredita que a criação de uma sociedade da informação é essencial para os desenvolvimentos social, cultural e econômico de nações, comunidades, instituições e indivíduos no século XXI. A instituição encoraja a promoção do letramento informacional, caracterizando-o como um direito humano universal que garante o acesso à informação e definindo-o como

a luz da sociedade da informação, iluminando os cursos do desenvolvimento, da prosperidade e da liberdade. Ele empodera as pessoas em todos os caminhos da vida para buscar, avaliar, usar e criar informações de forma efetiva com vistas a atingir seus objetivos pessoais, sociais, ocupacionais e educacionais. Este é um direito humano fundamental no mundo digital e promove a inclusão social em todas as nações. (UNESCO, 2013)

A Association of College \& Research Libraries, doravante ACRL, definiu um conjunto de cinco padrões que determinam o quão letrada informacionalmente é uma pessoa. Esses padrões se baseiam em cinco componentes principais: necessidade de informação, acesso, 
avaliação, uso e ética. A ACRL acredita que o desenvolvimento de habilidades relacionadas a esses padrões é útil para que os alunos percebam as etapas das quais precisam se apropriar na interação com a informação. Segundo a associação,

um indivíduo letrado informacionalmente é capaz de determinar a extensão da informação necessária, acessar a informação eficiente e eficazmente, avaliar criticamente a informação e sua fonte, incorporar as informações selecionada a sua base de conhecimento, utilizar a informação de forma a alcançar um objetivo específico, compreender as questões econômicas, sociais e legais que envolvem o uso da informação e o acesso ético à mesma. (Association of College \& Research Libraries, 2000)

O primeiro padrão se concentra na identificação da necessidade da informação, bem como no reconhecimento dos tipos e da quantidade de informação necessários. Isso inclui estar apto não só para perceber a necessidade iminente de pesquisa, mas também conhecer os recursos disponíveis para localização da informação desejada e escolher aqueles mais apropriados para pesquisa do tema. Neste padrão há ainda a preocupação a respeito da reavaliação da necessidade de informação em função do que já se sabe a respeito da mesma.

O segundo padrão foca no acesso à informação. Pode-se pensar que este é um procedimento trivial, em função da abundância de fontes e das variadas ferramentas de busca disponíveis, mas aqui se discute a localização da informação mais adequada, e não o maior número de informações ou as informações mais rapidamente recuperadas. Devem ser discutidas neste momento as diferentes formas de pesquisa empregadas nos diferentes campos de conhecimento, além de se refletir sobre a escolha das ferramentas e estratégias de busca mais eficazes para acesso às informações desejadas. É importante reforçar que existem métodos e sistemas variados de pesquisa, e não somente as máquinas de busca, como o Google, por exemplo. Há também que se refinarem as estratégias e chaves de busca conforme necessário.

O terceiro padrão foca em dois tipos de avaliação. O primeiro está relacionado à avaliação das fontes resultantes da pesquisa de modo a garantir que são legítimas e autênticas. É necessário um cuidado especial quando a pesquisa é realizada em ambiente virtual, pois, nesse contexto, praticamente qualquer pessoa pode publicar o que quiser. Também é importante refletir criticamente para que se possa identificar informações tendenciosas, preconceituosas ou manipuladoras. O segundo tipo de avaliação diz respeito à mineração das informações localizadas para que sejam extraídas aquelas que podem contribuir de maneira eficiente à pesquisa. É preciso, ainda, sintetizar as informações de modo a produzir novas ideias e conceitos, e não simplesmente copiá-las sem que se proceda nenhuma reflexão. 
Como nenhuma pesquisa é realizada sem motivação, o quarto padrão está relacionado ao uso das informações localizadas para um fim específico. Faz-se aqui a reflexão a respeito do que já se sabia e do que foi descoberto, com a intenção de produzir um trabalho de pesquisa ou tomar uma decisão, por exemplo. Nesta etapa também poderão surgir novas necessidades de pesquisa, impulsionadas pelo que foi descoberto e ainda não está claro. Nesse caso, inicia-se um novo ciclo e passa-se novamente pelos padrões previamente descritos.

O último padrão discute os aspectos éticos e legais relacionados ao uso das informações encontradas. Não se trata somente de incluir referências bibliográficas às fontes citadas de modo a evitar o plágio, mas também de fazer uso ético das informações de modo a não incorrer em problemas políticos ou de propriedade intelectual ou outros relacionados à liberdade de expressão, por exemplo. É preciso manter a integridade da informação citada e não manipulá-la ou modifica-la de modo a alcançar objetivos específicos.

Ao percorrer as cinco etapas constitutivas do processo de letramento informacional, o indivíduo terá a oportunidade não só de realizar uma pesquisa, mas também de refletir criticamente sobre as informações com as quais irá se deparar. Trata-se, assim, de um exercício importante na formação de indivíduos capazes de aprender a aprender, ou seja, aptos a buscar e usar a informação eficaz e eficientemente (GASQUE, 2012).

\section{METODOLOGIA}

Esta é uma pesquisa qualitativa e, como tal, reconhece que os aspectos relacionados à língua são moldados com base em fatores sociais, culturais e situacionais. Trata-se do paradigma ideal para que sejam iniciadas reflexões a respeito desses fatores e preocupa-se com aspectos subjetivos e experiências ou percepções individuais. O estudo aqui apresentado configura-se, assim, numa pesquisa interpretativista na qual o pesquisador é o principal instrumento de medida e análise (DORNYEI, 2007).

As atividades selecionadas para o estudo pertencem ao volume um da coleção "WAY TO GO!”. A obra foi elaborada pelos professores Claudio Franco e Kátia Tavares, da Universidade Federal do Rio de Janeiro, e aprovada no Programa Nacional do Livro Didático de 2015, com vigência até 2017. Tratam-se de livros para o ensino da língua inglesa no Ensino Médio e, segundo os autores, os principais destaques da obra são (a) a variedade de gêneros textuais; (b) a abordagem de temas de relevância social; (c) o uso da língua inglesa 
em diferentes práticas sociais; (d) a ênfase na formação do leitor crítico e (e) o ensino da língua em articulação com as demais disciplinas do currículo.

Os três livros que integram a coleção contêm oito unidades que se estruturam em torno de temas atuais e relevantes. A escolha pelo primeiro volume da coleção para análise das atividades se deve à crença de que o letramento informacional precisa ser trabalhado o mais cedo possível nos diferentes estágios de educação formal. Isso não significa, entretanto, que não haja espaço para que esse letramento continue a ser trabalhado nas atividades dos outros volumes. Ao contrário, quanto mais envolvido com a prática consciente do uso da informação, mais críticos e autônomos tenderão a ser os alunos.

A análise dos dados apresenta sugestões de complementação de uma das atividades propostas no primeiro volume da coleção. A intenção dessas sugestões é aperfeiçoar os procedimentos de pesquisa e promover a conscientização a respeito do uso da informação. Para tanto, utilizam-se como referência os padrões para construção da competência em letramento informacional propostos pela Association of College \& Research Libraries descritos na seção anterior e brevemente resumidos na figura a seguir.

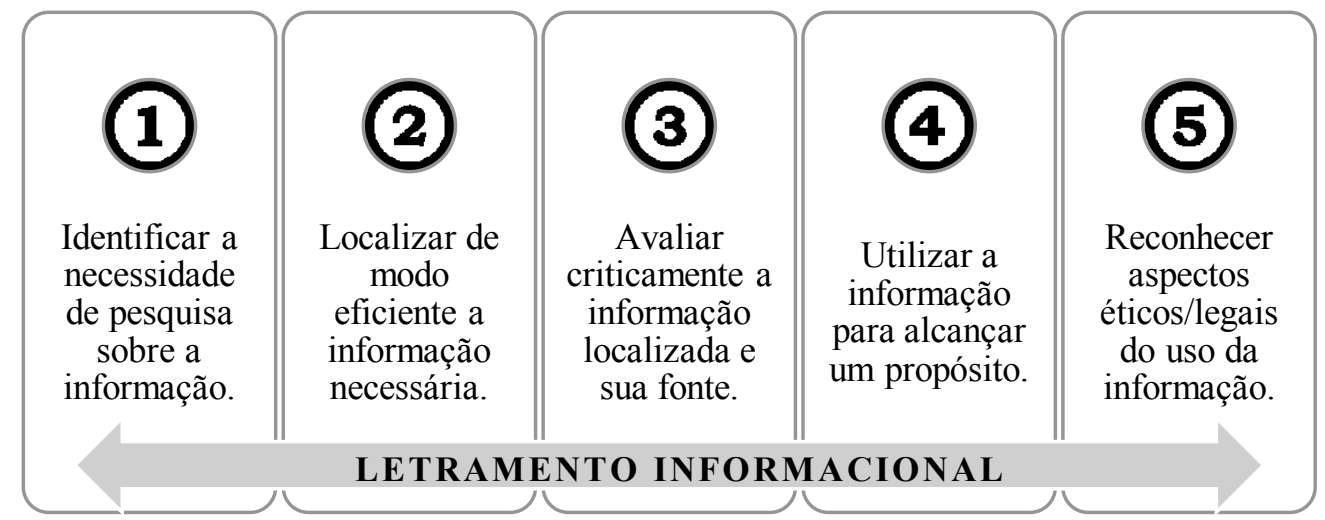

Figura 1: Padrões que formam a base para o letramento informacional

Vale ressaltar que a atividade selecionada para este estudo é apenas uma das muitas atividades presentes na coleção que propiciariam o exercício reflexivo para prática do letramento informacional. A intenção da discussão apresentada a seguir é apenas mostrar um exemplo prático da teoria apresentada anteriormente e incentivar um movimento que permita minimizar as diversas dificuldades vivenciadas por aqueles que precisam acessar informações com alguma finalidade específica. 


\section{PROPOSTA DE COMPLEMENTAÇÃO}

A atividade utilizada como base neste estudo pertence à Unidade 1, intitulada "Studying with technology”, do primeiro volume da coleção. Trata-se de um exercício da seção "Language in use", na página 21, que apresenta um infográfico sobre o uso da Internet nos Estados Unidos. A tarefa dos alunos é completar duas lacunas do texto com as formas afirmativa e negativa do verbo to spend no Presente Simples, conforme se vê na figura a seguir.

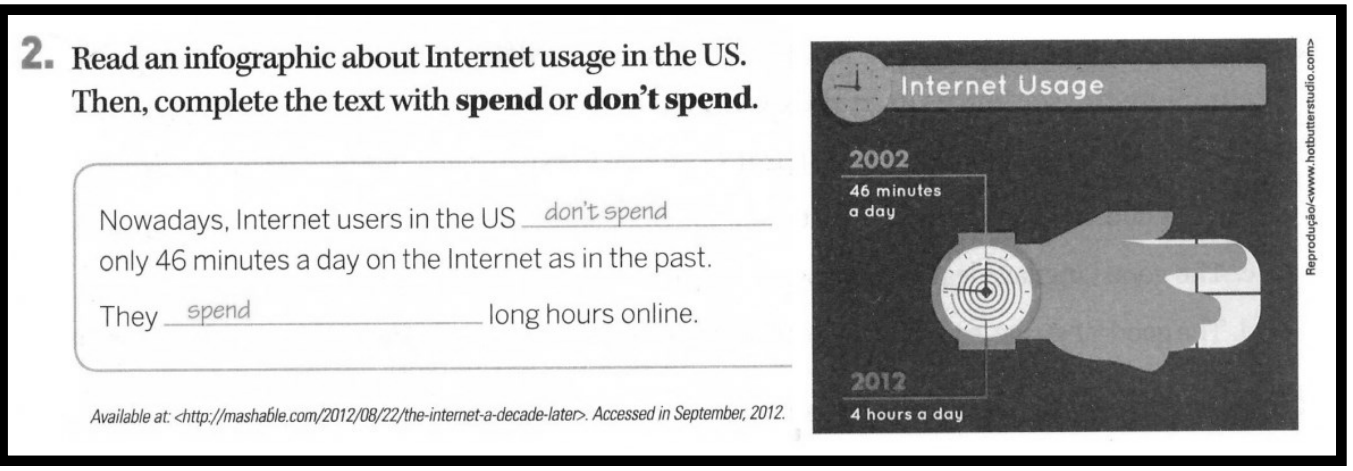

Figura 2: Atividade da seção "Language in use" - TAVARES e FRANCO (2015, p.21)

Como complementação desta atividade, pode-se sugerir aos alunos a criação de um infográfico que apresente informações sobre o uso da Internet no Brasil. É bastante improvável que a informação sobre o tempo diário de conexão dos brasileiros à rede seja conhecida; o que dará ao professor a oportunidade de trabalhar o primeiro padrão do letramento informacional, que estimula o aluno a identificar a necessidade de pesquisa sobre a informação. Como, para muitos alunos, a atividade "fazer pesquisa" é quase sempre entendida como "fazer pesquisa na Internet", a identificação da necessidade de investigação é também um bom momento para reflexão sobre os locais onde as informações podem ser obtidas para além da rede mundial de computadores.

A utilização da Internet para realização da atividade proposta dará ao professor a oportunidade de trabalhar com o segundo padrão do letramento informacional, que estimula a localização eficiente da informação necessária. Um problema recorrente quando se deseja fazer uma pesquisa é que, muitas vezes, não se dedica tempo suficiente à reflexão em torno do que se deseja pesquisar. O resultado dessa falta de ponderação gera uma enorme frustração, pois a implicação é que se leva muito mais tempo do que o necessário fazendo a pesquisa e os resultados obtidos são, em geral, confusos e pouco relevantes. Tem-se aqui, portanto, o 
momento ideal para exercício da definição dos diferentes segmentos a serem fornecidos às máquinas de busca e para observação dos diferentes resultados obtidos a partir de cada um deles. É possível iniciar a pesquisa por "Internet usage in Brazil"; já que o sintagma "Internet usage" está presente no texto da atividade, e seguir refinando a busca com termos como "Internet usage in Brazil in 2015", "Internet usage in Brazil per day" ou, ainda, "Daily Internet usage in Brazil'. É importante ressaltar que a lista de resultados a ser obtida depende da máquina de busca escolhida para a pesquisa. Utilizando o Google, por exemplo, a consulta ao segmento "Internet usage in Brazil" retornou 12.600 resultados. Com o Bing, entretanto, a mesma consulta retornou apenas 39 resultados, mesma quantidade retornada pela pesquisa feita com o Yahoo! Brasil (consultas realizadas em 20 de junho de 2015).

Outro aspecto a considerar é a possibilidade de realizar a pesquisa fornecendo sintagmas em português. No Google, a busca por "Uso da Internet no Brasil em 2015" traz mais de 24 milhões de resultados, sendo o terceiro deles um relatório atualizado com informações bastante relevantes sobre o tema em questão ${ }^{1}$. Trata-se de um bom exemplo, pois permite que seja trabalhada a necessidade de verificação da fonte das informações as quais se tem acesso. Nesse site, o autor do texto esclarece que as informações ali apresentadas foram divulgadas por outra fonte, a agência de marketing social We Are Social. Vale ressaltar que, como as informações dos gráficos apresentados estão em inglês, o foco principal da atividade, que é a prática do letramento informacional através do ensino da língua inglesa, não se perde.

A variedade de resultados obtidos na busca ajudará a configurar a situação ideal para analisar não somente a informação dada pelos sites localizados na pesquisa, mas também a integridade e a confiabilidade dos mesmos. É o momento, então, de se trabalhar com o terceiro padrão, que discorre sobre a avaliação crítica da informação e das fontes que a citam. Um bom ponto de partida é a avaliação da eficiência dos segmentos fornecidos para a pesquisa na localização da informação desejada. Resultados ruins podem indicar a necessidade de revisão dos sintagmas fornecidos como chave para a busca. Outro exercício importante é o de comparação das diferentes fontes com relação à adequação dos dados obtidos à finalidade inicial da pesquisa. O infográfico original mostra o crescimento, nos Estados Unidos, do tempo de acesso diário à Internet em um intervalo de dez anos, 2002 a 2012. Para reproduzir a ideia original com números sobre o Brasil, será necessário visitar os

\footnotetext{
${ }^{1} \mathrm{O}$ site ao qual se faz referência é o pmweb.com.br, uma empresa de automação de marketing que disponibiliza uma série de estudos de caso e relatórios em sua página na Internet. O endereço completo para acesso ao caso que apresenta os dados sobre o uso da Internet no Brasil está disponível no endereço http://blog.pmweb.com.br/a-internet-no-brasil-em-2015/, acessado em 20 de junho de 2015.
} 
diferentes sites listados no resultado da busca a fim de localizar os dados sobre o mesmo período.

Selecionadas as informações para a construção do infográfico, é chegado o momento de usá-las para se alcançar o objetivo inicial da pesquisa. Essa é a finalidade do quarto padrão, que encoraja a utilização da informação pesquisada para alcançar um propósito específico. Neste exercício, propõe-se a construção coletiva de um infográfico, uma vez que as reflexões sobre o processo de pesquisa previamente descritas serão realizadas em grupo. A atividade grupal não representa uma dificuldade para a prática do letramento informacional, visto que a principal intenção é ampliar a compreensão sobre as etapas presentes em uma pesquisa. Se houver a intenção futura de avaliar o resultado das discussões, o professor pode formar pequenos grupos e solicitar que novos infográficos sejam criados. Podem ser apresentados outros aspectos relacionados ao uso da Internet; como os listados nos diferentes sites lidos para coleta dos dados para o infográfico inicialmente proposto. São exemplos de possíveis temas, relacionados ao Brasil ou a outros países ${ }^{2}$ : número de usuários da Internet, percentual de penetração da Internet, duração mensal média do tempo de acesso à Internet, número de usuários do Facebook, hábitos de uso da Internet e redes sociais mais populares.

O quinto e último padrão a ser trabalhado está relacionado ao reconhecimento dos aspectos éticos e legais do uso da informação. O principal tema a ser discutido nesta etapa diz respeito ao plágio; que é a prática de uso de trabalhos e ideias de terceiros sem que o devido crédito lhes seja atribuído. É importante reforçar nos alunos que o processo educacional contempla a incorporação de ideias de diferentes fontes nos trabalhos, mas que a mesma não pode ser feita sem que os autores dessas ideias sejam citados. Na atividade proposta, será necessário incluir informações sobre o site de onde foram retirados os dados para a construção do infográfico. Além da discussão sobre o plágio, pode-se incluir um momento para que se apresente a maneira correta de citar uma fonte de Internet nas referências bibliográficas; o que pode iniciar um novo ciclo de pesquisa caso o professor opte por buscar, junto com os alunos, informações sobre o tema na Internet.

\section{CONSIDERAÇÕES FINAIS}

Como as tecnologias continuam a transformar o mundo, é importante separar as ferramentas utilizadas no acesso à informação das habilidades necessárias à compreensão e ao

\footnotetext{
${ }^{2}$ Propor que os novos infográficos apresentem os mesmos dados sobre o Brasil e outros países pode criar uma boa atmosfera para reflexão e debate.
} 
uso criterioso da mesma. O letramento informacional é muito mais do que uma competência tecnológica ou um conhecimento sobre como realizar pesquisas em ambiente virtual. Ele encoraja a reflexão e a adoção de uma postura crítica no contexto do crescente volume de informações disponíveis através de diferentes meios.

Realizar pesquisas é uma tarefa solicitada com frequência ao longo do processo educacional. Entretanto, ao contrário de atividades como ler, escrever, somar e subtrair, tal atividade não costuma ser formalmente ensinada. Com isso, percebe-se nos alunos uma enorme falta de habilidade na produção de pesquisas adequadas; o que gera frequente insatisfação nos professores, em especial por conta do exagerado plágio nas produções.

O que se pretende com este artigo é mostrar a possibilidade que os professores têm de explorar o material didático de maneira a ajudarem seus alunos a minimizar as dificuldades relacionadas à pesquisa. $\mathrm{O}$ exemplo apresentado aborda uma atividade da disciplina Língua Inglesa, mas qualquer outra pode se apropriar da proposta descrita a fim de propiciar a prática que conduzirá ao letramento informacional. O objetivo principal deste texto é contribuir para o desenvolvimento de uma competência básica essencial para o sucesso na sociedade da informação, capaz de formar indivíduos críticos e autônomos que farão uso consciente das informações das quais dispõem.

\section{REFERÊNCIAS}

Association of College \& Research Libraries. Information Literacy Competency Standards for Higher Education. Chicago: ALA, 2000. Disponível em $<$ http://www.ala.org/acrl/standards/informationliteracycompetency $>$. Acesso em 25 jun. 2015.

CAREGNATO, S. E. O desenvolvimento de habilidade informacionais: o papel das bibliotecas universitárias no contexto da informação digital em rede. Revista de Biblioteconomia \& Comunicação, Porto Alegre, v. 8, p. 47-55, 2000.

COPE, B., KALANTZIS, M. (Eds.). Multiliteracies: Literacy learning and the design of social futures. London: Routledge, 2000.

DOYLE, C. S. Information Literacy in an Information Society: a concept for the information age. New York: Syracuse University, 1994.

DORNYEI, Z. Research Methods in Applied Linguistics. Oxford, OUP: 2007.

GASQUE, K. C. G. D. Letramento Informacional: pesquisa, reflexão e aprendizagem. Brasília: Faculdade de Ciência da Informação/Universidade de Brasília, 2012. 
SOARES, M. Letramento: um tema em três gêneros. Belo Horizonte: Autêntica, 1998.

TAVARES, K. C. A.; FRANCO, C. P. WAY TO GO!, São Paulo: Ática, 2013.

UNESCO. Media and Information Literacy (MIL) in Brazil. Disponível em $<$ http://www.unesco.org/new/en/brasilia/communication-and-information/access-toknowledge/media-and-information-literacy/>. Acesso em 20 jun. 2015.

\section{A AUTORA}

Luciana do Amaral Teixeira é Tecnóloga em Processamento de Dados (UCB, 1996), Bacharel em Letras (PUC-Rio, 2005) e Mestre em Estudos da Linguagem (PUC-Rio, 2008). Atua como professora de Informática na FAETEC e na Universidade Estácio de Sá, e é professora da disciplina Língua Estrangeira (Inglês) na Secretaria Municipal de Educação do Rio de Janeiro. Tem interesse na produção de material didático para desenvolvimento do letramento informacional.

E-mail: luciana.teixeira@globo.com 